\title{
infância, imagem e formação docente: entre experiências, saberes e poderes na educação infantil
}

\author{
césar donizetti leite ${ }^{1}$ \\ universidade estadual paulista júlio de mesquita filho, brasil \\ andréia regina de oliveira camargo ${ }^{2}$ \\ professora ebtt do núcleo de educação infantil paulistinha, brasil
}

resumo

As reflexões acerca da formação docente e os modos pelos quais elas são trabalhadas nos contextos educacionais têm grande importância tanto pela urgência do tema como também pela multiplicidade de modos de ser tratada pelos professores. A partir de pesquisas de produção de imagens desenvolvidas com crianças e professoras no âmbito da Educação Infantil, o presente texto irá refletir sobre os processos formativos da docência na Educação Infantil. Nesse cenário algumas perguntas são relevantes: $O$ que pode a imagem nos processos formativos? Em que pode a formação de professores ajudar a pensar acerca da infância e das práticas educativas com crianças pequenas? Em que pode a infância ajudar a refletir sobre os trabalhos de formação de professores? Este texto objetiva realizar uma experiência de pensamento, operando com as imagens produzidas, com palavras (linguagem), infância, imagem e formação docente; possibilitar aberturas para pensar a criança, os educadores e as educadoras, a escola, os saberes, os fazeres, os poderes, os protocolos de ações, o que e como fazer com as crianças; compor possibilidades que extrapolam o determinado e legalizado. Tomam-se como pressupostos teóricos autores como Giorgio Agamben, Gilles Deleuze e Michel Foucault.

palavras-chave: experiências imagéticas; infância; 'formação' docente; educação infantil.

childhood, image and teacher education:

between experiences, knowledge and powers in early childhood education

abstract

The reflections around teacher training and the means by which it is treated in the educational contexts have major importance, due to the urgency of the topic as well as the multiplicity of ways to be dealt along with the teachers. From researches of images production, developed with children and teachers in the ambit of early childhood education, this text will reflect on the formative processes of teachers in the childhood education. In this context, there are a few relevant questions: what can the image do in the formative processes? In which ways may the teacher training help us to think about the childhood and the educational practices with little children? By which means may the childhood help us to think the work of teacher training. In this way, using the produced images, this text aims to operate in the circulation movement of the thought itself, in which the thought can, in its exteriority, experiment with words (language), childhood, image and teacher training, enabling ruptures to think about the child, the educators, the school, the knowledge, the doing, the powers, the action protocols, what to do with the children and how to deal with them, composing possibilities that overflow what is

\footnotetext{
${ }^{1}$ E-mail: mvhleite@uol.com.br

2 E-mail: alglmachado@gmail.com
} 
infância, imagem e formação docente: entre experiências, saberes e poderes na educação infantil

determined and legalized. As theoretical basis, we take authors such as G. Agamben, G. Deleuze e Michel Foucault.

keywords: imagetic experiences; childhood; teacher training; early childhood education.

\section{infancia, imagen y formación docente: entre experiencias, saberes y poderes en la educación infantil}

resumen

Las reflexiones acerca de la formación docente y los modos por los cuales ellas son trabajadas en los contextos educacionales tienen gran importancia tanto por la urgencia del tema como también por los múltiples modos de ser desarrollados por profesores y profesoras. A partir de pesquisas de producción de imagen desarrolladas con niños y niñas y profesores en el ámbito de la Educación Infantil, el presente texto reflexiona sobre los procesos formativos de la docencia en la Educación Infantil. En este escenario algunas preguntas son relevantes: ¿Qué puede la imagen en los procesos formativos? ¿En qué puede la formación de profesores y profesoras ayudar a pensar la infancia y las prácticas educativas con niños y niñas pequeñas? ¿En qué puede la infancia ayudar a reflexionar sobre los trabajos de formación de profesores y profesoras? Este texto tiene por objetivo realizar una experiencia de pensamiento, trabajando con imágenes producidas, palabras (lenguaje), infancia, imagen y formación docente; posibilitar aberturas para pensar a los niños y niñas, los educadores y las educadoras, la escuela, los saberes, los haceres, los poderes, los protocolos de acciones, qué y cómo hacer con los niños y niñas, componer posibilidades que extrapolen lo determinado y lo legalizado. Se toma como supuestos teóricos autores como Giorgio Agamben, Gilles Deleuze y Michel Foucault.

palabras clave: experiencia-imagen; infancia; formación docente; educación infantil. 


\section{infância, imagem e formação docente: entre experiências, saberes e poderes na educação infantil}

\section{introdução}

Eu tinha vontade de fazer como os dois homens que vi sentados na terra escovando osso. No começo achei que aqueles homens não batiam bem. Porque ficavam sentados na terra o dia inteiro escovando osso. Depois aprendi que aqueles homens eram arqueólogos. E que eles faziam o serviço de escovar osso por amor. E que eles queriam encontrar nos ossos vestígios de antigas civilizações que estariam enterrados por séculos naquele chão. Logo pensei de escovar palavras. Porque eu havia lido em algum lugar que as palavras eram conchas de clamores antigos. Eu queria ir atrás dos clamores antigos que estariam guardados dentro das palavras. Eu já sabia também que as palavras possuem no corpo muitas oralidades remontadas e muitas significâncias remontadas. Eu queria então escovar as palavras para escutar o primeiro esgar de cada uma. Para escutar os primeiros sons, mesmo que ainda bígrafos. Comecei a fazer isso sentado em minha escrivaninha. Passava horas inteiras, dias inteiros fechado no quarto, trancado, a escovar palavras. Logo a turma perguntou: o que eu fazia o dia inteiro trancado naquele quarto? Eu respondi a eles, meio entresonhado, que eu estava escovando palavras. Eles acharam que eu não batia bem. Então eu joguei a escova fora.

Manoel de Barros

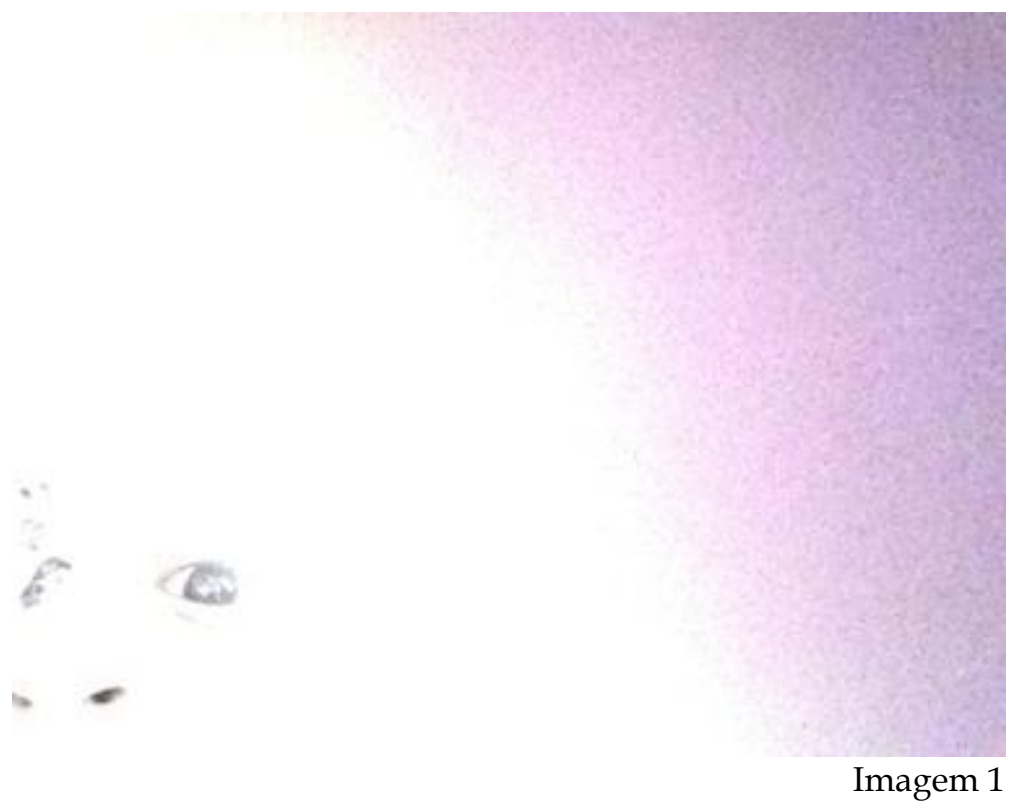

Fonte: Arquivo Grupo Imago

Formar, capacitar, identidade do professor, perfil, explicar, facilitar, mediar, refletir. Deformar, de-formar; deformação, de-formação; reformar, re-formar; transformar, trans-formação. Transmitir, dialogar, explicar, facilitar, preparar, 
guiar, orientar. Identidade profissional, identidade do professor, identidade, diversidade. Singularidade, exposição, experiência, multiplicidade. Professar.

Em nossa época muitos têm sido os modos de falar, pensar, escrever acerca da formação docente, muitas têm sido as maneiras de abordar esse tema tão povoado-tangenciado-demarcado por outros temas, outros espaços, outros lugares, outros territórios. Muitos cenários são colocados, apresentados, discutidos, refletidos. Muito esperamos dos professores, muito depositamos nos professores, criamos-idealizamos perfis, identidades, ditamos e orientamos, definimos. Fazemos lembrar, circular, descrever o tempo todo o que é importante, necessário, fundamental para a educação. Nesses movimentos subtraímos, abstraímos, esquecemos...

De um modo muito particular, os trabalhos de formação docente têm se apresentado de muitas e diferentes formas e tido contornos bastante específicos em cada um dos seus exercícios. Verificamos em nossas pesquisas ${ }^{3}$, juntamente com professores de Educação Infantil, que em uma época como a nossa, povoada de discursos sobre o que e como fazer com as crianças nas práticas educativas, os discursos, as teorias e os protocolos de ações distanciam os professores da experiência com a escola, do cotidiano da escola e de seus modos de produção de sentidos para as práticas educativas. Esses protocolos de ações modulam práticas, atitudes e posturas, separam a educação das experiências, produzindo nelas um discurso acerca da realidade, construindo um conjunto de regras, de ditos e não ditos que regulam o conhecimento e produzem atitudes, moldando posicionamentos e criando práticas e ordens de poderes, hierarquizados ou não, das práticas docentes. De alguma forma, é como se em nossos programas formativos fôssemos, com nossos conceitos/nossas verdades, agenciando práticas de poderes que colonizam mundos carentes de conhecimentos e reflexão.

\footnotetext{
3 “Do outro lado da cerca: Experiências com imagens, infância e educação. Reflexões e olhares para o Desenvolvimento Infantil a partir de produções imagéticas de professores e crianças" (apoio FAPESP e CNPQ). "Infância, Pesquisa e Experiência: Reflexões e olhares para o Desenvolvimento Infantil a partir de produções imagéticas de professores e crianças" (apoio FAPESP e CNPQ). "Ação, Câmera, Ação, Câmera, Luz: Entre imagens e olhares - Experiência de infâncias e montagens" (apoio FAPESP e CNPQ).
} 
Nesse cenário, esses regimes de poderes, agenciados por regimes de verdades, dirigem os modos de ser como educador, modos dados e definidos por discursos; essas práticas se conectam na educação a modos de controle da vida social - pela educação - através dos discursos e das enunciações criadas em nosso cotidiano; assim, "a verdade não tem mais que ser produzida. Ela terá que se representar e se apresentar cada vez que for procurada" (FOUCAULT, 2009, p.117), e é nesses movimentos que as ditas verdades acabam por constituir modos prévios de estar no mundo, modos dados, fundados de lidar com a educação. Ou ainda, para além desses modos, o que nos parece é que escovar as palavras acerca da formação de professores não pode ser outra coisa que também escovar os 'saberes' e as 'práticas de poderes' postos nessas relações.

Nas pesquisas que temos desenvolvido em Escolas de Educação Infantil, verificamos que, muitas vezes, as concepções de infância, os modos de lidar com as crianças, as experiências educativas e, sobretudo, os trabalhos de formação docente são povoados por esses saberes e essas práticas de poderes presentes nos discursos que circulam nesse universo. Esses oscilam em muitas frentes. Destacaremos aqui duas delas: (1) uma série de aglomerados de 'índices' que geram Políticas Públicas, Projetos Político-Pedagógicos, que regulam os diferentes modos de estar na escola e tornam as práticas um amontado de clichês que separam, distanciam e fragmentam os diferentes corpos (corpo do professor, dos funcionários, da equipe gestora, das famílias, das Políticas Públicas, entre outros) em suas relações com o trabalho com crianças pequenas na Educação Infantil; (2) discursos acerca das práticas na Educação Infantil sobre o que e como fazer com as crianças no cotidiano escolar. Em um sentido foucaultiano (2012), essas formações discursivas que modulam ações, emergem, fazem circular e naturalizar práticas com as crianças, são marcadas por um cotidiano da escola povoado por uma multiplicidade que o tempo todo escapa, foge ao que está dito e naturalizado pelos discursos. Posto de outra forma, há discursos que, de um lado, se ocupam com a produção de modos e formas que abarcam, supostamente, atitudes gerais, globais, burocráticas, jurídicas, leis, estatutos, discursos que determinam práticas e modos de trabalhar na Educação e, mais especificamente, na Educação Infantil; e, por 
infância, imagem e formação docente: entre experiências, saberes e poderes na educação infantil

outro lado, 'fluxos', agenciamentos coletivos e singulares, perspectivas que margeiam, que são marginais às políticas públicas, mas, e por isso mesmo, vivas no cotidiano da escola.

Nesses trabalhos, temos observado também que essas políticas públicas que derivam para supostos protocolos de ações distanciam os professores da própria vida em torno da escola, do cotidiano da escola, como se a linguagem ali presente estivesse desvinculada das experiências vividas e vívidas no universo da Educação Infantil. Esses discursos, seja pelas práticas que indicam modos de lidar com as crianças ou ainda pelas que prezam por uma atitude reflexiva, consolidadas nos mais diferentes tipos de linguagem, estão dissociados da experiência, pois todas indicam um modelo idealizado do professor e de sua formação, e tornam assim a linguagem um código vazio, sem vida. Observamos aqui que a perspectiva de Gilles Deleuze (2011b), ao falar das unidades da língua, faz coro a isso que apresentamos até aqui, pois a língua é, antes de tudo, política, já que

não existe língua-mãe, e sim tomada de poder por uma língua dominante, que ora avança sobre uma grande frente, ora se abate simultaneamente sobre centros diversos. Pode-se conceber várias maneiras de uma língua se homogeneizar, se centralizar: a maneira republicana não é a mesma que a real, e não é a menos dura. (DELEUZE, 2011b, p. 49)

Em nossos trabalhos com cinema e educação, por vezes verificamos que na escola e com ela, na pesquisa e com ela, muitas vezes linguagem e experiência estão dissociadas, apresentando-se como um código vazio, sem vida. É através da experiência que entramos na linguagem, e é na infância que experimentamos a vida na sua mais plena intensidade, distante das amarras da razão. Sendo assim, e de modo geral, podemos dizer que nunca temos a totalidade da linguagem e de seus supostos sentidos em nossas mãos, e sempre nos pegamos pautados pelas perdas das experiências, quando ficamos imersos na linguagem, na busca dos sentidos. Portanto, linguagem e experiência se encontram na infância, nas suas possibilidades de aberturas e inacabamento.

Dito de outra forma, como se o sentido, sobretudo os demarcados pelas Políticas Públicas, pelas Leis, pelos documentos, fosse um ato de violência com a 
própria força que o pensamento experimenta, uma força que apodera o pensamento; ou ainda, como se o sentido insistisse no pensamento um campo representativo, um campo seguro, um campo de poder; mas também como se o pensamento buscasse, fora dele e fora do próprio homem, um modo de poder existir; como se o pensamento fosse um prolongamento do homem na exterioridade de sua experiência.

Este texto objetiva operar no movimento de circulação do próprio pensamento, quando ele pode, em sua exterioridade, experimentar com palavras (linguagem), infância, imagem e formação docente. Tomaremos, como espaços compositivos, imagens produzidas por crianças de Educação Infantil e o poema “Escovas", de Manoel de Barros.

\section{escovando a pesquisa}

Eu tinha vontade de fazer como os dois homens que vi sentados na terra escovando osso. No começo achei que aqueles homens não batiam bem. Porque ficavam sentados na terra o dia inteiro escovando osso. Depois aprendi que aqueles homens eram arqueólogos. E que eles faziam o serviço de escovar osso por amor. E que eles queriam encontrar nos ossos vestígios de antigas civilizações que estariam enterrados por séculos naquele chão. Logo pensei de escovar pesquisas. Porque eu havia lido em algum lugar que as pesquisas eram conchas de clamores antigos. Eu queria ir atrás dos clamores antigos que estariam guardados dentro das pesquisas. Eu já sabia também que as pesquisas possuem no corpo muitas oralidades remontadas e muitas significâncias remontadas. Eu queria então escovar as pesquisas para escutar o primeiro esgar de cada uma. Para escutar os primeiros sons, mesmo que ainda bígrafos. Comecei a fazer isso sentado em minha escrivaninha. Passava horas inteiras, dias inteiros fechado no quarto, trancado, a escovar pesquisas. Logo a turma perguntou: o que eu fazia o dia inteiro trancado naquele quarto? Eu respondi a eles, meio entresonhado, que eu estava escovando pesquisas. Eles acharam que eu não batia bem. Então eu joguei a escova fora.

Manoel de Barros 


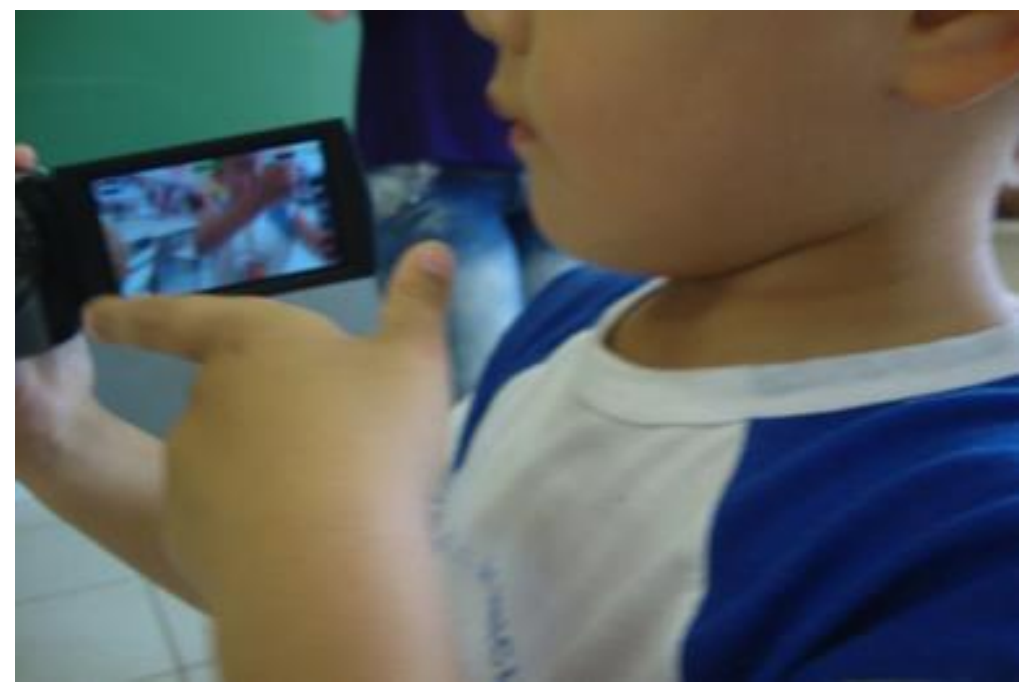

Imagem 2

Fonte: Arquivo Grupo Imago

O audiovisual tem sido, com frequência, utilizado como um recurso em trabalhos no campo da Educação. Desde os já demarcados filmes como instrumento para discussão de conteúdos até a produção de filmes por alunos e professores dentro da escola, entre um e outro, inúmeras são as iniciativas e as formas de trabalhar com esse 'instrumental' cada dia mais presente no universo escolar. Em trabalhos ligados à formação e, mais especificamente, à formação de professores $^{4}$, a instrumentalização do cinema tem sido comum e possui vários modos de utilização.

Tomaremos como ponto de partida desta nossa reflexão pesquisas que temos desenvolvido, em escolas da Rede Pública de Educação Infantil, com produção de imagens por crianças e professoras. De modo geral, esses estudos possuem como objetivo refletir sobre o poder da imagem e das produções imagéticas realizadas por crianças e professoras/monitoras no espaço de uma creche e de uma pré-escola de Rede Pública. Nesses trabalhos, entre outras coisas, temos podido observar que, para além dos cenários mais demarcados pelos modos dados e definidos nas Políticas Públicas e nos programas formativos

\footnotetext{
${ }^{4}$ O Dossiê "Cinema, educação e seus processos de formação", da revista ETD, v. 19, n.2, 2017, apresenta uma série de textos em que essa discussão está presente. Também destacamos o livro organizado por Adriana Fresquet, Cinema e Educação: A Lei 13.006 - Reflexões. Perspectivas e Propostas. Editora Universo Produção.
} 
desenvolvidos com esses professores, outras possibilidades se apresentam nos trabalhos na Educação Infantil.

Destacaremos aqui três dos resultados desses estudos: 1- as pesquisas de produção de imagens com crianças nos sugerem outros modos para pensar o 'pesquisar' com crianças pequenas, a pesquisa na escola, os trabalhos com professores; 2 - as produções de imagens e as próprias imagens abrem a possibilidade para pensarmos acerca de outras temporalidades no desenvolvimento da criança e, bem por isso, outros 'currículos' na Educação Infantil; 3 - as produções de imagens e as próprias imagens apresentadas pelas crianças abrem perspectivas para um outro olhar, para uma educação ainda por vir, uma educação que atravessa não somente o trabalho diretamente com as crianças, mas também, e de modo geral, o trabalho com as professoras.

Salientamos que utilizamos nesses estudos, como metodologia de pesquisa, a entrega de câmeras fotográficas, filmadoras e tablets às crianças e às professoras/monitoras, que, com os equipamentos em mãos, produziam 'livremente' fotografias (imagens digitais) e filmagens - conjunto que será chamado aqui de 'imagens'. Assim equipadas, tanto as crianças como as professoras tiveram, durante 4 anos, a oportunidade de produzir cerca de 27 mil imagens: aproximadamente 23 mil fotografias (imagens digitais) e 4 mil filmes. Esse foi, durante esse percurso, o material utilizado para o desenvolvimento de trabalhos pelas professoras, diretoras e coordenadoras de Educação Infantil.

Temos chamado essas pesquisas de 'relatos de minorias', de pesquisa 'menor', pesquisa 'infantil' ou, mais especificamente, "pesquisa como experiência". Esse modo de pesquisar se caracteriza por uma perspectiva orientada no sentido de dar visibilidade para aquilo que 'acontece', 'emerge' no próprio percurso da pesquisa e não busca analisar e/ou interpretar os dados coletados, mas sim criar um campo de experiências de pensamento com imagens, filmagens, infâncias, com crianças e professoras. Essas experiências de pensamento não objetivam o eterno, mas sim 'microanálises' que deem visibilidades a agenciamentos de 'linhas agitadas', na perspectiva da "formação do novo, a emergência, ou o que Foucault chamou de 'atualidade'" (DELEUZE, 
infância, imagem e formação docente: entre experiências, saberes e poderes na educação infantil

2013, p.113) - um efetivo exercício de pensamento, um exercício de 'pensar com... (com imagens, com crianças, com professoras, com educação infantil)'.

Em reuniões de trabalhos pedagógicos com professores, coordenadores e diretores de Educação Infantil, longe de procurar encontrar contribuições do cinema para a educação e dessa para o cinema, objetivamos mapear os modos de afetação do cinema e do filme e seus desdobramentos.

O fato é que, mais especificamente em nossos estudos com as professoras, observamos que muito daquilo que parecia atuar em um campo do sensível estava modulado por modos predefinidos para ver e pensar as imagens, maneiras predeterminadas de ser e de estar no mundo, ou ainda, dito de outro modo, aquilo que chamamos muitas vezes de afetação já vinha predeterminado, predefinido, modulado, algoritmizado por formas efetivas no campo das tecnologias da imagem.

Nesse contexto e no cenário dessas reflexões acerca dos processos de modulação presentes nas imagens, demarcadas por discursos e formações discursivas, acabamos por conectar essas reflexões a outros estudos foucaultianos, sobretudo os desenvolvidos no campo da biopolítica, pois, apesar das muitas variações deste conceito, grosso modo podemos dizer que o conceito de biopolítica apresentado por Michel Foucault $(2008,2009)$ se caracteriza por ser uma noção de um poder produtivo e presente, que aparentemente se apresenta a nós em meio a uma perspectiva de liberdade e de suposta autonomia, estabelecendo-se por meio de uma série de estratégias que investem na vida humana, em suas dimensões biológica, subjetiva e social.

O conceito em si poderia ser apresentado como a irrupção da naturalidade da espécie no interior da artificialidade política de uma relação de poder. Ou ainda, o ingresso da vida nua no domínio da vida qualificada, da vida em comunidade, da vida política. Percebemos uma intensificação dessas estratégias biopolíticas, em razão de alguns fatores, um dos quais apresentaremos aqui: uma convergência entre biopolítica e capitalismo avançado. Nessa perspectiva, podemos dizer que o capitalismo, em suas estratégias biopolíticas de controle sobre a vida, se interessa por esta como modo inesgotável de reserva de criação e 
invenção, transbordando para a vida cotidiana os limites das relações de invenção e criação e transformando a vida em mercadoria, fazendo coincidir consumo e forma de vida, colocando-nos cada vez mais em um modelo de um real criado por discursos que subtraem nossa experiência com o mundo.

Assim, podemos dizer que as tecnociências se comportam como estratégias avançadas e eficientes de operar, através das tecnologias da imagem e da informação, uma espécie de modulação, fragmentação da vida, do espaço, do tempo e do corpo. Essa entrada nos estudos do cinema e de sua relação com a educação nos levou, em um curto espaço de tempo, a trabalhar primeiramente na reflexão sobre as 'fronteiras' e sobre elas como lugares de passagem, travessia, como lugares que ligam, que produzem encontro. Mas temos trabalhado também nas fronteiras entre pesquisa, cinema e educação e, talvez por isso, temos podido encontrar visibilidade no que escapa às modulações desse efeito das tecnociências, tornando assim necessário 'escovar' os modelos interpretativos e as análises representacionais muitas vezes presentes nas pesquisas em educação.

No esforço de pensar acerca dos 'entres' que ocorrem nessas práticas de pesquisa e de experiência de pensamento nas pesquisas com cinema e educação, os lugares em que ensaiam, os espaços em que se inscrevem, os modos com que se apresentam são, muitas vezes, sobrepostos, justapostos, em um campo aberto e ainda por ser percorrido, explorado, narrado, inventado, contado. No campo das pesquisas que realizamos, podemos dizer também que não basta apenas sobrepor estes termos, estas palavras, estas ideias, mas é preciso ir além, sobretudo no campo das pesquisas com crianças e das pesquisas com crianças na Educação Infantil. Nesse cenário, decidimos que era necessário experimentar com o cinema e com as imagens; era preciso perguntar, se perguntar: $\mathrm{O}$ que pode o cinema? $\mathrm{O}$ que pode a imagem? O que pode a Educação? O que podem crianças e professoras com câmeras nas mãos nos oferecer a pensar sobre a Educação?

\section{escovando a infância}

Eu tinha vontade de fazer como os dois homens que vi sentados na terra escovando osso. No começo achei que aqueles homens não batiam bem. 
Porque ficavam sentados na terra o dia inteiro escovando osso. Depois aprendi que aqueles homens eram arqueólogos. E que eles faziam o serviço de escovar osso por amor. E que eles queriam encontrar nos ossos vestígios de antigas civilizações que estariam enterrados por séculos naquele chão. Logo pensei de escovar infância. Porque eu havia lido em algum lugar que a infância eram conchas de clamores antigos. Eu queria ir atrás dos clamores antigos que estariam guardados dentro da infância. Eu já sabia também que a infância possui no corpo muitas oralidades remontadas e muitas significâncias remontadas. Eu queria então escovar a infância para escutar o primeiro esgar de cada uma. Para escutar os primeiros sons, mesmo que ainda bígrafos. Comecei a fazer isso sentado em minha escrivaninha. Passava horas inteiras, dias inteiros fechado no quarto, trancado, a escovar infância. Logo a turma perguntou: o que eu fazia o dia inteiro trancado naquele quarto? Eu respondi a eles, meio entresonhado, que eu estava escovando infância. Eles acharam que eu não batia bem. Então eu joguei a escova fora.

Manoel de Barros

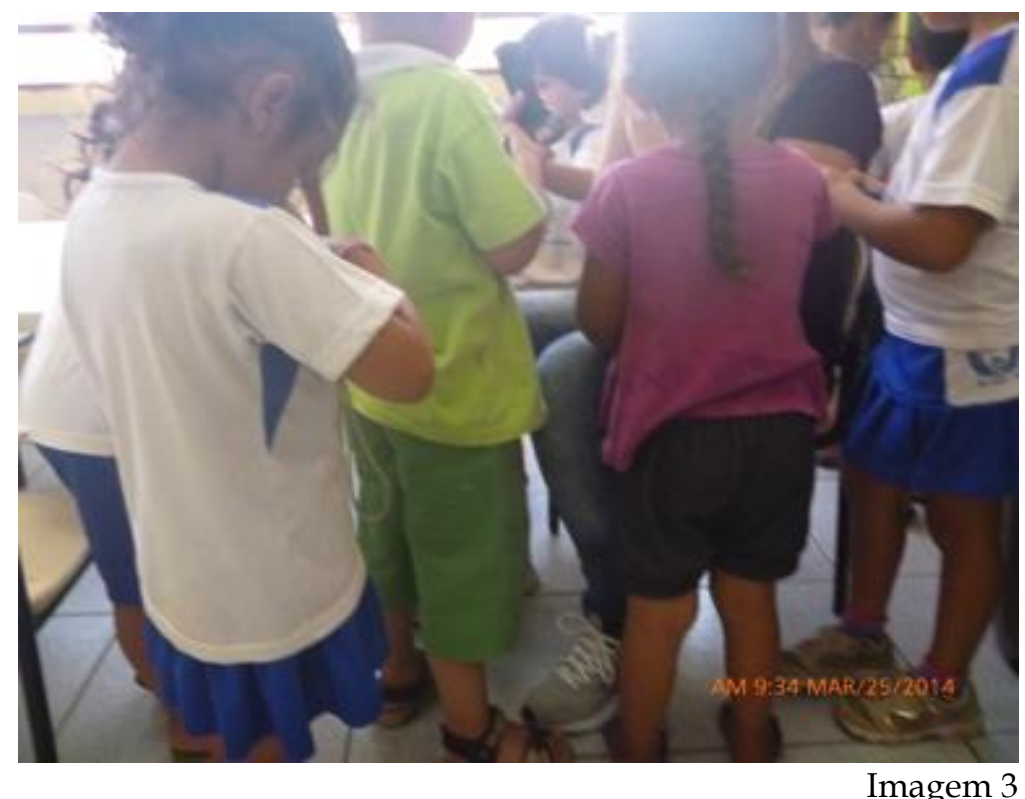

Fonte: Arquivo Grupo Imago

No pensamento ocidental, a imagem da infância está atrelada a uma ideia cronológica do vir a ser das crianças, um degrau fundante para o futuro cidadão, relação com um ser sem forma alguma no presente, material maleável e à disposição para modulações. A perspectiva que, na modernidade, assume dois modelos que se desenharam como 'modelos tradicionais e alternativos' dentro da educação, que são atravessados por uma mesma origem, que, desde a Antiguidade liga infância e educação, e o pressuposto filosófico ao pressuposto 
pedagógico, que veio a ser demarcado por aquilo que acabamos denominando de 'pensamento de Platão'.

Nesse pressuposto, a ideia de formação e, nesse sentido de educação, passa necessariamente por uma noção de 'monstruosidade da infância' e pela necessidade de reformulação do espírito humano e infantil. Esta perspectiva acaba sendo o que, desde a Grécia Antiga, norteou uma ideia de educar como um ato de tirar a infância da criança e a criança da infância, com o propósito de levá-las à vida adulta. “O espírito do homem não lhes é (não nos é) um dado de maneira completa e deve ser reformado. O monstro dos Filósofos é a infância. Ela também é sua cúmplice. A criança lhes (nos) diz que o espírito não é um dado, mas que é um possível" (GAGNEBIN, 1997, p. 84).

As observações de Gagnebin nos remetem também a uma reflexão histórica sobre nossas práticas educativas com as crianças, em que observamos aproximações entre nossas formas contemporâneas de olhar para a infância e de lidar com as crianças e as ideias oriundas da Grécia Antiga, criando assim nosso projeto formativo, presente em nossas práticas educativas nas escolas e fora dela. Ou seja, se podemos fazer algum tipo de conexão entre essas formas e o atravessamento histórico dessa perspectiva, podemos certamente dizer que aquilo que aparentemente se apresenta como dispersão nos discursos produz, na realidade das práticas sociais, um determinado tipo de regularidade acerca da noção de infância e dos modos de lidar com a criança.

Esses modos, que frequentemente podem ser chamados de saberes (da Filosofia, da Psicologia, da Sociologia, da Antropologia, da Didática, entre outros) sobre as crianças e a educação, são especificamente discursos que se efetivam em práticas de poderes sob uma perspectiva da infância. Nesse caso específico podemos dizer que as diferenças presentes na relação com a criança foram, ao longo de um tempo, sendo efetivadas em uma relação de poder e demarcando territórios de uma relação entre um superior e um inferior, entre o adulto e a criança, entre o professor e o aluno e, finalmente, entre o 'formador' e o professor.

Deste pressuposto talvez advenha o primeiro movimento de uma noção de devir e de uma perspectiva de ver a criança, o in-fans, como aquele que não é, mas 
que será; ou seja, vemos a criança como um ser inacabado, em formação, e desse mesmo pressuposto temos um modelo de pensamento que orientará, na modernidade, ciências como a Psicologia, da qual uma gama de 'conhecimentos' sustentará as formações discursivas no trabalho com a criança e com os professores. Dito de outro modo, nesse sentido, trabalhar com a infância e com a criança, e por que não dizer, com o professor é trabalhar sempre em uma perspectiva de uma ausência, talvez a ausência de fala, na própria etimologia da palavra in-fans, da ausência como carência, como falta. E, ainda, o que nos parece relevante e problemático nisso tudo é o modo com que, em contrapartida, vemos o adulto como um ser pronto, acabado, formado - dotado de razão e dono das possibilidades de indicar caminhos.

Esses modelos, apesar de se apresentarem de formas diferentes, partem de um mesmo pressuposto, o que visa controlar e definir modelos e caminhos educativos que serão seguidos, numa relação temporal sucessiva, quantitativa, de continuidade, entre o passado, o presente e o futuro. Modelos que são pilares, que objetivam criar, em si mesmos, uma educação pautada em um devir dado para a infância, para a criança e para a educação.

Porém, em nossos trabalhos temo-nos pautado em outras possibilidades acerca dessas temáticas. Diferentemente do que apresentamos até o presente momento e, como nos apresenta Agamben (2005), a infância é pensada não como um período do desenvolvimento humano, mas como uma condição da experiência. A ideia desse autor nos remete para além da questão cronológica e nos lança à abertura de outras possibilidades.

Nos trabalhos que temos desenvolvido na educação infantil, temos observado, a partir das experiências imagéticas das crianças e das professoras, que pensar a infância para além dos espaços institucionalizados, cronologicamente controlados e curricularmente gradeados, nos apresenta várias 'linhas de fuga' para além do tempo chrónos da escola e dos currículos, dentre outros movimentos distintos dos que estão roteirizados no "o que e como fazer" nas práticas educativas. Temos tido a oportunidade de observar a potência criativa de outros tempos, da intensidade aiônica da vida humana, de uma temporalidade que não é 
quantificável, regulável, sucessiva, mas “[...] marcada por outra relação - intensiva - com o movimento. [...] não há sucessão nem consecutividade, mas a intensidade da duração" (KOHAN, 2007, p.87), pois a infância pode ser pensada "como intensidade, um situar-se intensivo no mundo; um sair sempre do 'seu' lugar e se situar em outros lugares, desconhecidos, inusitados, inesperados" (KOHAN, $2004)^{5}$.

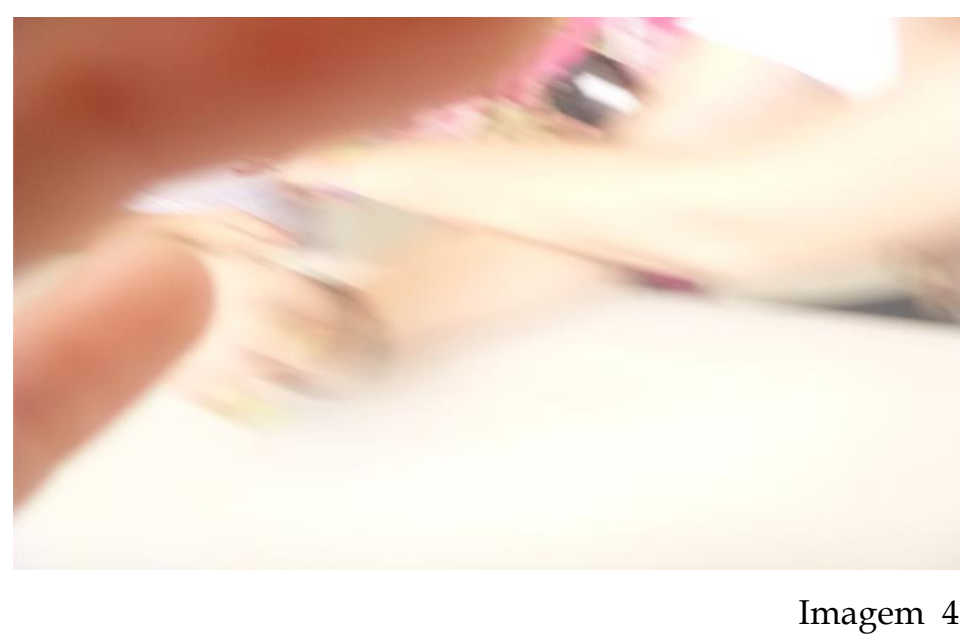

Fonte: Arquivo Grupo Imago

"Escovar" a infância talvez seja isso, talvez seja produzir algum tipo de visibilidade para essas intensidades, talvez seja procurar escapar dos campos discursivos que controlam, regulam os fazeres com as crianças e com os professores, seja um 'ato dermatológico' de povoar a pele com a sensibilidade dos toques, dos desfocamentos que as imagens, as representações, os olhares certeiros nos oferecem sobre a criança.

\section{escovando a formação docente}

Eu tinha vontade de fazer como os dois homens que vi sentados na terra escovando osso. No começo achei que aqueles homens não batiam bem. Porque ficavam sentados na terra o dia inteiro escovando osso. Depois aprendi que aqueles homens eram arqueólogos. E que eles faziam o serviço de escovar osso por amor. E que eles queriam encontrar nos ossos vestígios de antigas civilizações que estariam enterrados por séculos naquele chão. Logo pensei de escovar a formação docente. Porque eu havia

\footnotetext{
${ }^{5}$ Disponível em: http://www.educacaopublica.rj.gov.br/biblioteca/educacao/0184.html. Acesso em: 12 out. 2017.
} 
lido em algum lugar que a formação docente eram conchas de clamores antigos. Eu queria ir atrás dos clamores antigos que estariam guardados dentro da formação docente. Eu já sabia também que a formação docente possui no corpo muitas oralidades remontadas e muitas significâncias remontadas. Eu queria então escovar a formação docente para escutar o primeiro esgar de cada uma. Para escutar os primeiros sons, mesmo que ainda bígrafos. Comecei a fazer isso sentado em minha escrivaninha. Passava horas inteiras, dias inteiros fechado no quarto, trancado, a escovar formação docente. Logo a turma perguntou: o que eu fazia o dia inteiro trancado naquele quarto? Eu respondi a eles, meio entresonhado, que eu estava escovando formação docente. Eles acharam que eu não batia bem. Então eu joguei a escova fora.

Manoel de Barros

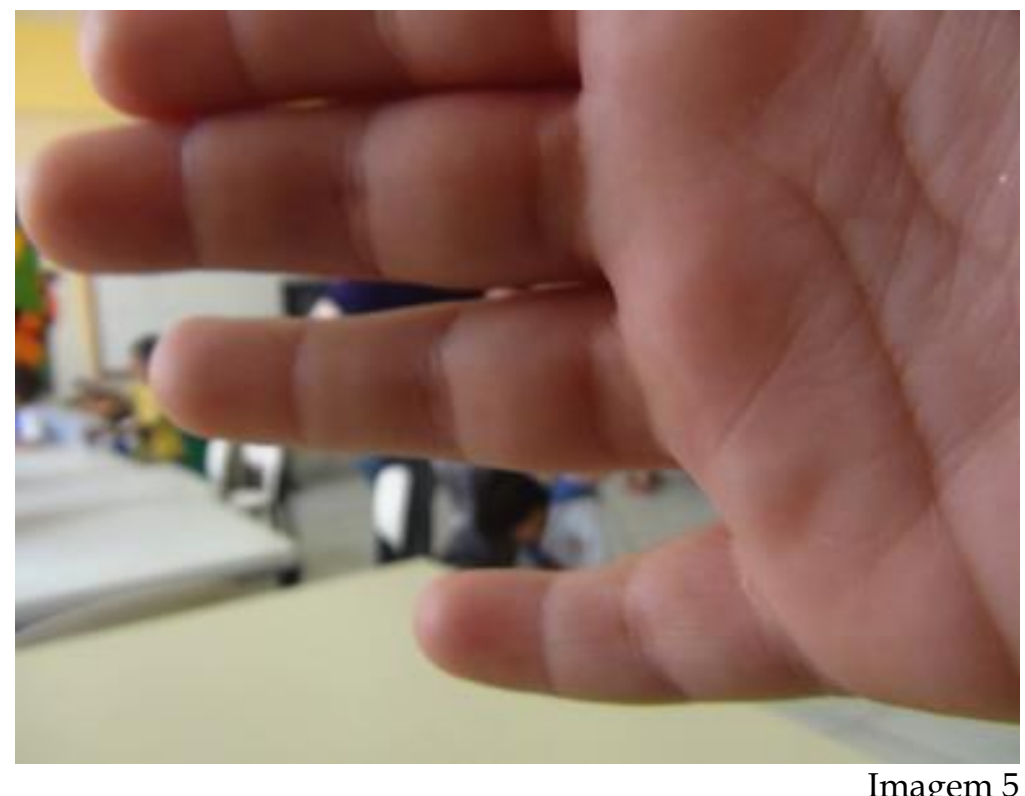

Fonte: Arquivo Grupo Imago

No intuito de "escovar" a formação docente na escola de Educação Infantil, a produção de imagens com crianças, educadoras e educadores (professoras e auxiliares de educação) em momentos de "formação", potencializam discussões sobre concepções de criança, de infância e suas relações com as práticas educativas, mas também fazem emergir questões acerca de políticas públicas, de usos dos espaços, de modos de olhar, de povoamento de multiplicidades de experiências quando somos permeados pelo que vemos e pelo que não vemos.

Num processo de construção coletiva do Projeto Político-Pedagógico de uma das escolas onde desenvolvemos nossas pesquisas, as imagens captadas por uma criança de 3 anos de idade, cega desde o nascimento, dispararam discussões para aquilo que na imagem está fora do visualmente intencional e convida 
educadores e educadoras a produzirem visualidades naquilo que a imagem apresenta.

Imagens que mobilizam, criam movimentos, traçam contornos, vibram em cores, se apresentam como deformações, sugerindo um pensar a infância e a criança para além da instituição, de suas regras, padrões, formatos, rotinas.

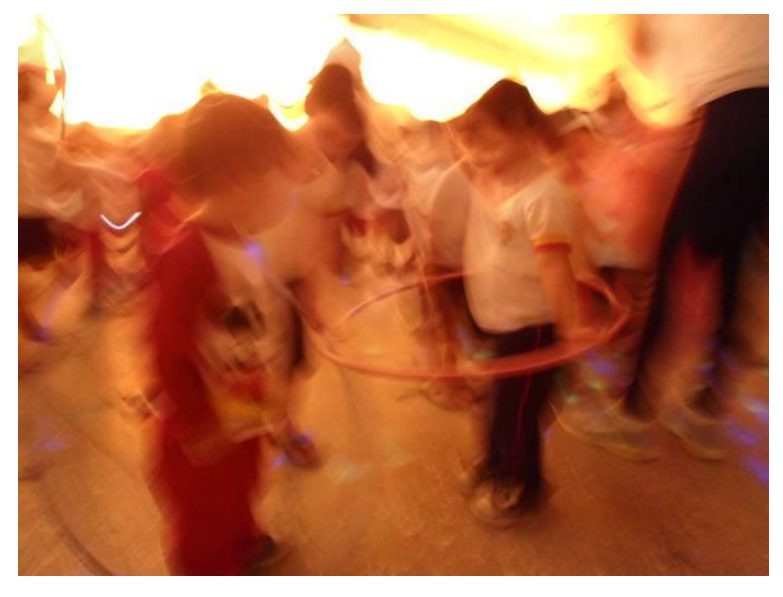

Imagem 6

Fonte: Arquivo Grupo Imago

As imagens nos apresentam a infância enquanto potência, experiência, devir, devir-criança, fora dos vínculos etários, cronológicos, normalizados, normatizados

[...] sem pacto, sem falta, sem fim, sem captura; ela é desequilíbrio; busca; novos territórios; nomadismo; encontro; multiplicidade em processo, diferença, experiência. Diferença não-numérica; diferença em si mesma; diferença livre de pressupostos. Vida experimentada; expressão de vida; vida em movimento; vida em experiência. (KOHAN, 2005, p.253)

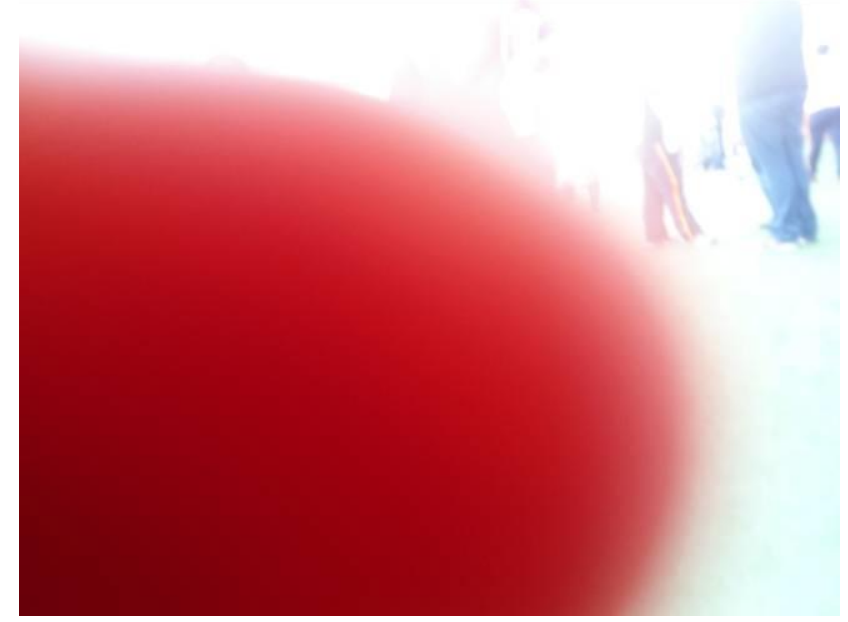


Provocadas por essas imagens de olhares "não obstruído[s] pelos clichês" (SCHÉRER, 2009, p.209), educadoras e educadores, com celulares nas mãos, adentram em experiências imagéticas na ambiência da escola e seus arredores, num processo de criação, e com as imagens produzem imagens da escola, caminham, observam, escolhem, recortam, enquadram, clicam, verificam, selecionam, apagam... compartilham...
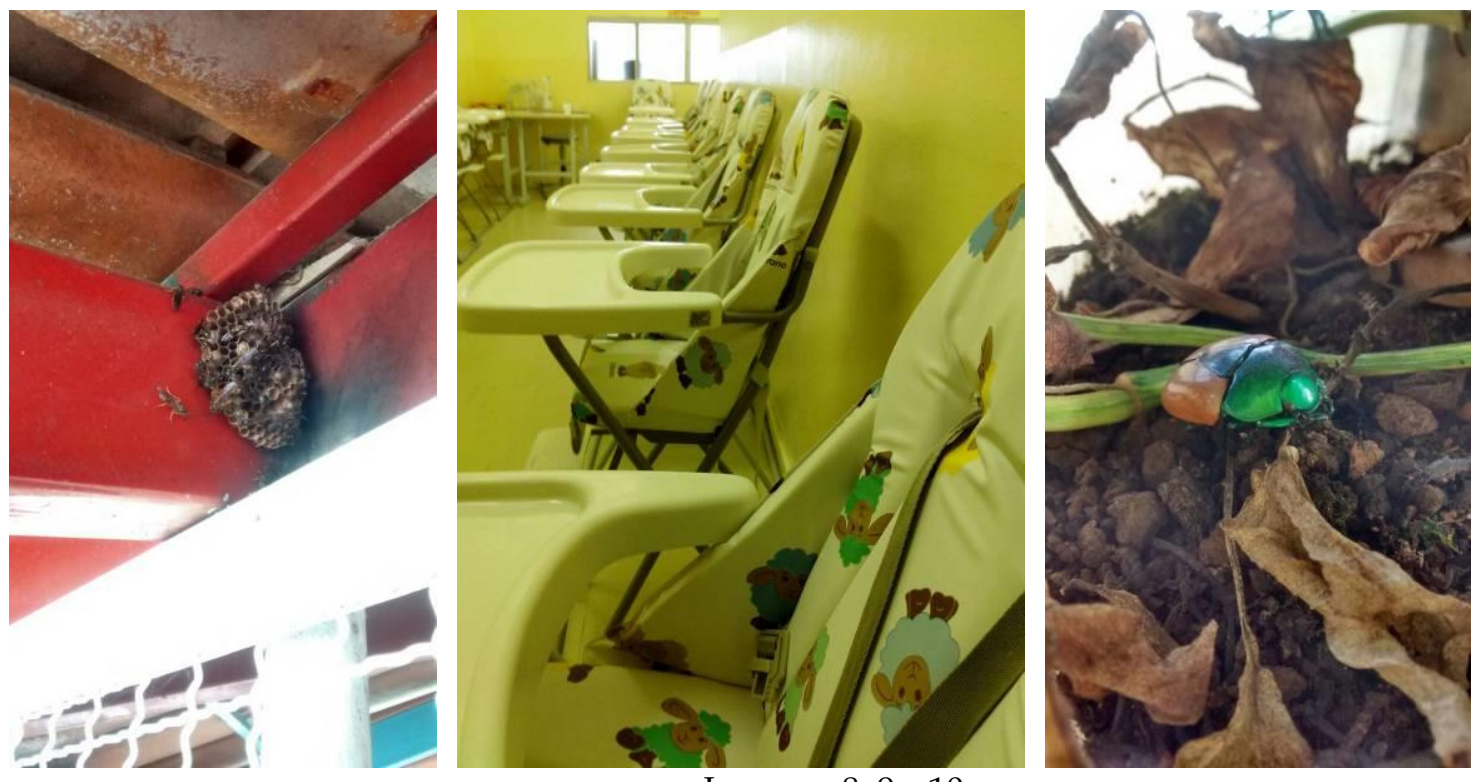

Imagens 8,9 e 10

Arquivo Grupo Imago

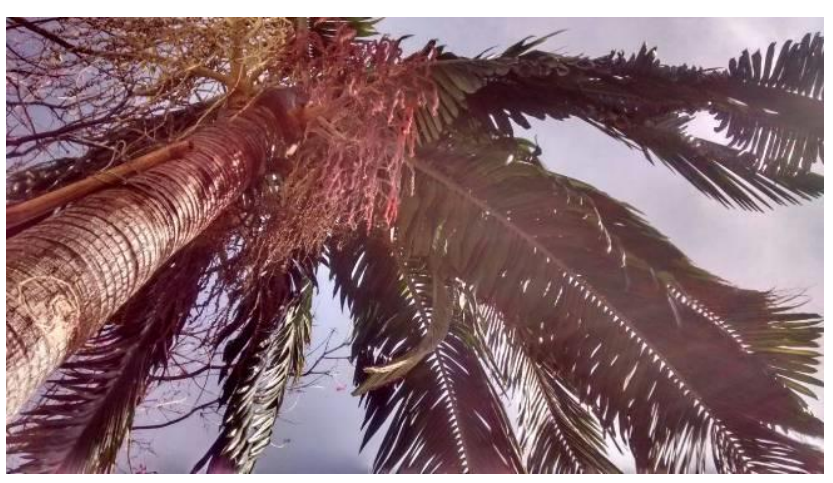

Imagem 11

Fonte: Arquivo Grupo Imago

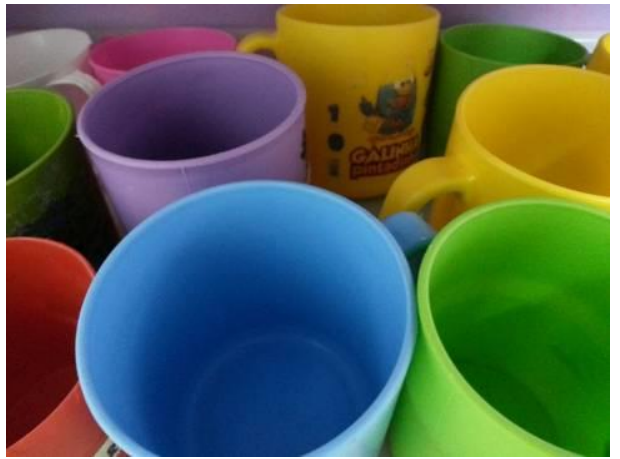

Imagem 12

Fonte: Arquivo Grupo Imago

Os detalhes do cotidiano são captados com novos contornos, formatos, perspectivas; por olhares distintos dos usuais para os lugares, os objetos, os seres, os espaços que constituem a escola da primeira infância, mas que ficam fora do campo perceptual no cotidiano da instituição. Uma possibilidade de pensar a 
educação no campo compositivo para um devir-criança para a educação e para a formação do professor.

Demarcamos aqui um ponto importante, pois não são novos modos, muitas vezes presentes, de pensar a infância, a criança e a formação do professor que estamos procurando trazer aqui; não é a infância como lugar 'romanceado' por discursos e práticas com as crianças, tão frequentes hoje em dia; não é a formação do professor que seja definida por um modo ou outro - nosso interesse é pensar relações possíveis entre a infância, a criança, a formação do professor, relações que nos apresentem a perspectiva de um 'devir-criança' como revelado por Deleuze, em Crítica e clínica:

A obra gaguejante de Biely, Kotik Letaiev, lançada num devircriança que não é eu, mas cosmos, explosão de mundo: uma invenção que não é a minha, que não é uma recordação, mas um bloco, um fragmento anônimo infinito, um devir sempre contemporâneo. (DELEUZE, 1997, p.129)

\section{aberturas}

"Escovar" pesquisa, infância e formação docente no contexto da Educação Infantil, com experiências imagéticas, possibilita aberturas para pensar a criança, os educadores e as educadoras, a escola. Nos trabalhos que temos desenvolvido, vemos emergir aberturas para o inesperado, o inusitado; para encontros com diferentes linguagens que extrapolam, que deslocam e desconfiguram nossas certezas e verdades acerca dos fazeres, dos saberes e dos poderes no trabalho com crianças pequenas. As rupturas, as brechas, as fissuras que temos encontrado desconstroem o determinado, o legalizado, o imposto nos padrões dos documentos.

Escovar as palavras, as imagens, a infância, a formação do professor, não objetiva verdades que fundamentem as práticas, que façam operar coerências teóricas. Escovar seria uma forma de compor, criar possibilidades que não sejam as já cristalizadas, fechadas, determinadas.

Nesse conjunto de coisas, talvez todo esse exercício seja um modo, uma forma de procurar produzir algum tipo de experiência de pensamento, 
experiências que possam dar algum tipo de visibilidade aos corpos crianças da escola, aos corpos infantis das crianças, a um tipo de corpo criança para a formação do professor, um corpo vivo presente nas imagens, um corpo que circule pelos olhares presentes no universo da Educação Infantil.

Dê-me portanto um corpo": esta é a fórmula da reversão filosófica. O corpo não é mais o obstáculo que separa o pensamento de si mesmo, aquilo que se deve superar para conseguir pensar. É ao contrário, aquilo em que ele mergulha e ou deve mergulhar o impensado, isto é, a vida. Não que o corpo pense, porém, obstinado, teimoso, ele força a pensar, e força a pensar o que escapa ao pensamento, a vida. (DELEUZE, 2007, p.225)

\section{referências}

AGAMBEN, Giorgio. Infância e história: destruição da experiência e origem da história. Belo Horizonte, MG: Editora UFMG, 2005.

BARROS, Manoel. Biblioteca Manoel de Barros (Coleção). São Paulo: LeYa, 2013.

DELEUZE, Gilles. Crítica e clínica. São Paulo: Editora 34, 1997.

DELEUZE, Gilles. A imagem tempo - cinema 2. São Paulo-SP: Brasiliense, 2007.

DELEUZE, Gilles. Mil platôs. São Paulo: Editora 34, 2011a. v 1.

DELEUZE, Gilles. Mil platôs. São Paulo: Editora 34, 2011b. v. 2.

DELEUZE, Gilles. Conversaçôes. São Paulo: Editora 34, 2013.

FOUCAULT, Michel. O nascimento da biopolítica. São Paulo: Martins Fontes, 2008.

FOUCAULT, Michel. Microfísica do poder. São Paulo: Graal, 2009.

FOUCAULT, Michel. A arqueologia do saber. 8. ed. Rio de Janeiro: Forense Universitária, 2012.

GAGNEBIN, Jeanne M. Sete aulas sobre linguagem, memória e história. Rio de Janeiro: Imago, 1997.

KOHAN, Walter O. A infância da educação: o conceito devir-criança. In: KOHAN, Walter O. (Org.). Lugares da infância: filosofia. Rio de Janeiro: DP\&A, 2004. Disponível em: <http://www.educacaopublica.ri.gov.br/biblioteca/educacao/0184.html> Não paginado. Acesso em: 12 out. 2017.

KOHAN, Walter. Infância: entre Educação e Filosofia. Belo Horizonte: Autêntica, 2005.

KOHAN, Walter. Infância, estrangeiridade e ignorância. Belo Horizonte: Autêntica, 2007.

SCHÉRER, René. Infantis: Charles Fourier e a infância para além das crianças. Belo Horizonte: Autêntica, 2009. 